\title{
Epidemiology of malaria in two Eastern districts of Nepal
}

\section{Parajuli $K^{1}$, Ghimire $\mathbf{P}^{2}$}

${ }^{1}$ Associate Professor, Institute of Medicine, Kathmandu, Nepal, ${ }^{2}$ Associate Professor, Central Department of Microbiology, Institute of Science and Technology, Tribhuvan University, Kathmandu, Nepal

\begin{abstract}
Backgrounds: Malaria is one of the major public health problems in Southeast Asia including Nepal having relatively high burden of malaria. Jhapa and Morang districts are malaria endemic plain area of South-eastern part of Nepal

Objectives: The evaluate the recent epidemiology of malaria situation in Jhapa and Morang districts, which are the districts in eastern Nepal with high transmission of malaria and to assess the knowledge, attitudes and practices of the people in prevention and treatment for malaria infection.

Materials and methods: This descriptive cross-sectional study was carried out with volunteer participation of suspected malaria patients seeking care at the government of Nepal managed primary health care centres located in 2 malaria endemic districts in eastern Nepal. Conventional Giemsa stained thick and thin blood smears prepared from finger prick blood were examined following standard protocols. Suspected patients' / attendants' knowledge on malaria, disease symptoms, prevention and control measures were assessed using a structured questionnaire. Chi square and Fisher exact test were used for statistical analysis of the data.

Results: Among the total 199 malaria suspected cases studied, 32 (16.1\%) cases were confirmed by microscopic findings; where, $P$. vivax was $12.6 \%$ (25/199) and $P$. falciparum in only $3.1 \%(6 / 199)$. The highest numbers of cases were in age group 20-29 years. Among the total positive cases $75 \%$ were male and $37.5 \%$ were labourers in occupation. Among the total cases, 32 had provided the history of recent travel to malaria endemic area in India, among them $43.8 \%$ $(\mathrm{P}<0.001)$ were found to be infected with the malarial parasites $(\mathrm{P}<0.001)$. Among the total cases, $69.7 \%$ showed some knowledge of malaria, among which fever was the most common symptom mentioned by $68.3 \%$. Occupation $(\mathrm{P}<0.001)$ and education $(\mathrm{P}<0.001)$ were found significantly associated with the knowledge on mode of transmission.

Conclusion: Jhapa district showed higher SPR than Morang, which indicated that Jhapa may be more malaria affected than Morang. Knowledge on malaria transmission and preventive measures are still lacking in deep villages, in spite of different efforts of the government. To improve the malaria morbidity in the districts, health education of the most marginalized people through audio visual methods may be beneficial.
\end{abstract}

Key words: Epidemiology, Malaria, Knowledge, Practice, Eastern Nepal

$\mathrm{M}$ alaria and poverty are intimately connected ${ }^{1}$, commonly recognised as a disease of poverty ${ }^{2}$. There were an estimated 247 million malaria cases among 3.3 billion people at risk in 2006, causing nearly a million deaths, mostly of children under 5 years. 109 countries were endemic for malaria in 2008, 45 within the WHO African Region ${ }^{3}$.

Malaria is a major public health problem in most tropical countries causing morbidity. Out of 11 countries of the South-East Asia Region (SEAR) 10 countries are malaria endemic. Around $60 \%$ of the global population at risk resides in SEA Region and accounts for $25 \%$ of the global morbidity and around $12 \%$ of the global mortality due to malaria ${ }^{4}$.
In Nepal, the incidence of malaria has now been reduced to 4,000-5,000 cases from about 15,000 cases annually. ${ }^{5}$ Out of the total population of 22.8 million, $73 \%$ (16.4 million) living in 65 districts of 5 developmental regions of Nepal are at risk of malaria ${ }^{6}$.

To achieve the national health policy targets, it is imperative to have active community participation to control malaria. Community participation in turn depends on people's knowledge and attitude towards the disease. An epidemiological study of malaria revealing its distribution in relation to different socioeconomic

Correspondence

Keshab Parajuli

Associate Professor

Maharajgunj Campus, Institute of Medicine,

Tribhuvan University, Kathmandu, Nepal

E-mail: keshabparajuli@hotmail.com 
predictors, knowledge and attitude of people at risks towards prevention and control can provide valuable information for formulation and implementation of effective malaria control strategy. Socioeconomic conditions of the community have direct bearing on the problem of malaria. Ignorance and impoverished conditions of people contribute in creating source and spread of malaria and hinder disease control strategy ${ }^{7,8}$.

Present study is aimed to evaluate the prevalence of malaria among patients seeking care with at least one symptom compatible to malaria along with the knowledge of the respondents on malaria transmission, prevention, protection measures, control and treatment in two malaria endemic districts (Jhapa and Morang) of eastern Nepal.

\section{Materials and methods}

This was a descriptive study and samples were collected between July to August 2007. The study was conducted in Jhapa and Morang districts which are situated in plain Terai of eastern Nepal. All the patients visiting the public health centres (PHCs) and district public health offices (DPHOs) during the study period with at least one symptom compatible to clinical malaria were included in the study upon agreeing (informed consent) to participate voluntarily in the study.

Giemsa stained thick/thin blood smears prepared from finger prick blood samples collected from each patients were examined for presence of malarial parasites following standard protocol ${ }^{9}$. In positive slides, Parasites were counted as per standard protocol ${ }^{10}$ using the formula Parasites $/ \mu 1=$ Total parasite count $/$ Total WBC count X 8000 (8,000 WBCs per micro litre blood).

Details on clinical symptoms, knowledge, attitude and practice (KAP) of the cases / attendants on prevention and treatment of malaria were collected using a well structured questionnaire. All collected data on patients KAP and slide microscopic finding were noted in the register and analyzed using appropriate statistical tool as per standard practice ${ }^{11}$.

\section{Results}

Prevalence of Malaria

Among the total of 199 samples analysed, 112 (56.3\%) were from Jhapa and 87 (43.7\%) from Morang district. $16.1 \%(32 / 112)$ cases were confirmed as malaria after microscopic investigation; out of which $12.5 \%$ (25/199) were Plasmodium vivax, 3.1\% (6/199) Plasmodium falciparum, and $0.5 \%(1 / 199)$ with mixed infection $(P$. vivax $+P$. falciparum). Slide Positivity Rate (SPR) in Jhapa and Morang was found 22.3\% (25/112) and 8.0\% (7/87) respectively (Table 1$)$.
Prevalence of malaria parasites in different groups In the study among the microscopy positive cases, $75 \%$ (24) were male, where male volunteers were $68 \%$ of the total cases studied. The most affected age group was 20-29 years with $31.3 \%$ positive cases followed by 30 39 years with $21.9 \%$ positives $(\mathrm{P}>0.05)$.

Parasite count: The parasite count ranged between $560-16,760 / \mu 1$. Among the total microscopy positive cases, $31.2 \%(9,1,0)$ had the parasite level below $2,000 / \mu 1,34.4 \%(7,3,1)$ cases contained parasites ranging $2,001-4,000 / \mu 1,12.5 \%(4,0,0)$ cases contained parasites ranging $4,001-6,000 / \mu 1,6.25 \%(2,0,0)$ cases parasites ranging $6,001-8,000 / \mu 1,3.12 \%(0,1,0)$ cases had parasites $8,000-10,000 / \mu 1$ and $12.5 \%(3,1,0)$ cases showed parasite count more than $10,000 / \mu 1$. (Figures in parentheses indicate cases with $P$. falciparum, $P$. vivax, mixed).

History of Travel: Among the total 199 cases studied, 63 respondents provided history of travel to known malaria endemic area in India and Nepal. Out of which $20(10.05 \%)$ cases were found to be malaria positive on microscopic examination of the blood. Among 63 respondents with travel history, 32 travelled to India, and 31 within country, where 14 (43.8\%) and 6 (19.4\%) cases were found to be infected respectively with the malarial parasites on microscopy.

Knowledge, Attitude \& Practice (KAP) of the respondents

Transmission by mosquito bite: Fourty one percent $(82 / 199)$ respondents have some knowledge on malarial transmission and it was significantly associated with occupation and education $(\mathrm{P}<0.001$,$) . Males (60 / 135)$ were better informed on transmission of malaria by mosquito than females, (Table 3).

Malaria can be treated using medicine: Knowledge on malaria as a treatable disease was significantly associated with age $(\mathrm{P}=0.014)$ and occupation $(\mathrm{P}=0.002)$, (Table 3 ). Among the total respondents, $17.6 \%$ (35) were not aware of whether malaria is treatable with the timely use of medicine.

Symptoms of malaria: Among the total respondents, $69.7 \%$ of respondents were aware on the symptoms of malaria. Fever $(68.3 \%)$, headache $(18.6 \%)$ were the commonest symptoms they mention. Other symptoms shivering and sweating were also mentioned.

Prevention from malaria infection: Out of 199 respondents, 49.7\% (99) respondents were not aware on prevention from malaria. $32.7 \%$ of the respondents were aware on use of bed nets. 
Table 1: Malaria prevalence among patients seeking care in two major malaria transmission districts of Nepal

\begin{tabular}{|c|c|c|c|c|c|c|}
\hline \multirow{3}{*}{ Particulars } & \multicolumn{4}{|c|}{ Districts } & \multirow{2}{*}{\multicolumn{2}{|c|}{ Total }} \\
\hline & \multicolumn{2}{|c|}{ Jhapa } & \multicolumn{2}{|c|}{ Morang } & & \\
\hline & No & $\%$ & No & $\%$ & No & $\%$ \\
\hline No of specimens analysed & 112 & 56.3 & 87 & 43.7 & 199 & 100 \\
\hline No of $P$. vivax positive specimens & 20 & 10.0 & 5 & 2.5 & 25 & 12.5 \\
\hline No of $P$. falciparum positive specimens & 5 & 2.6 & 1 & 0.5 & 6 & 3.1 \\
\hline No of specimens with mixed infections $(\mathrm{Pv}+\mathrm{Pf})$ & 0 & 0 & 1 & 0.5 & 1 & 0.5 \\
\hline Total positive specimens & 25 & 12.6 & 7 & 3.5 & 32 & 16.1 \\
\hline Slide positivity rate (SPR) & - & 22.3 & - & 8.0 & - & - \\
\hline
\end{tabular}

Table 2: Prevalence of malarial parasites in different groups

\begin{tabular}{|c|c|c|c|c|}
\hline \multirow[b]{2}{*}{ Descriptions } & \multicolumn{3}{|c|}{ Types of Parasites Detected } & \multirow[b]{2}{*}{ P value* } \\
\hline & P. vivax $(\mathrm{Pv})$ & $\begin{array}{c}\text { P. falciparium } \\
\text { (Pf) }\end{array}$ & Total & \\
\hline \multicolumn{5}{|l|}{ Age } \\
\hline$\leq 9$ & $2(8.0)$ & $0(0.0)$ & $2(6.3)$ & \multirow{7}{*}{0.748} \\
\hline $10-19$ & $4(16.0)$ & $1(16.7)$ & $5(15.6)$ & \\
\hline $20-29$ & $8(32.0)$ & $1(16.7)$ & $10(31.3)$ & \\
\hline $30-39$ & $5(20.0)$ & $2(33.3)$ & $7(21.9)$ & \\
\hline $40-49$ & $3(12.0)$ & $1(3.1)$ & $4(12.5)$ & \\
\hline $50-59$ & $3(12.0)$ & $0(0.0)$ & $3(9.4)$ & \\
\hline$\geq 60$ & $0(0.0)$ & $1(16.7)$ & $1(3.1)$ & \\
\hline \multicolumn{5}{|l|}{ Sex } \\
\hline Female & $7(28)$ & $1(16.7)$ & $8(25.0)$ & \multirow{2}{*}{0.715} \\
\hline Male & $18(72.0)$ & $5(83.3)$ & $24(75.0)$ & \\
\hline \multicolumn{5}{|l|}{ Occupation } \\
\hline Agriculture & $2(8)$ & $0(.0)$ & $2(6.3)$ & \multirow{8}{*}{0.632} \\
\hline Business & $2(8)$ & $0(.0)$ & $2(6.3)$ & \\
\hline Service & $0(.0)$ & $1(16.7)$ & $1(3.1)$ & \\
\hline Student & $6(24)$ & $1(16.7)$ & $8(25)$ & \\
\hline Labor & $8(32)$ & $4(66.7)$ & $12(37.5)$ & \\
\hline House maker & $3(12)$ & $0(.0)$ & $3(9.4)$ & \\
\hline Unemployed & $2(8)$ & $0(.0)$ & $2(6.3)$ & \\
\hline None & $2(8)$ & $0(.0)$ & $2(6.3)$ & \\
\hline \multicolumn{5}{|l|}{ Education } \\
\hline Illiterate & $5(20)$ & $2(33.3)$ & $7(21.9)$ & \multirow{3}{*}{0.818} \\
\hline Literate & $18(72.0)$ & $4(66.7)$ & $23(71.9)$ & \\
\hline None & $2(8.0)$ & $0(.0)$ & $2(6.2)$ & \\
\hline
\end{tabular}

Figures in parentheses indicate percentage with in types of parasites detected. 
Table 3: Knowledge, attitude and practice in different groups

\begin{tabular}{|c|c|c|c|c|c|c|c|c|}
\hline \multirow[t]{2}{*}{ Descriptions } & \multicolumn{2}{|c|}{$\begin{array}{c}\text { Mosquito is the } \\
\text { vector transmitting } \\
\text { malaria }\end{array}$} & \multirow[t]{2}{*}{ Total } & \multirow[t]{2}{*}{ P value } & \multicolumn{2}{|c|}{ Is malaria treatable } & \multirow[t]{2}{*}{ Total } & \multirow[t]{2}{*}{ P value } \\
\hline & No & Yes & & & Yes & $\begin{array}{l}\text { Don't } \\
\text { know }\end{array}$ & & \\
\hline \multicolumn{9}{|l|}{ Age } \\
\hline$\leq 9$ & $19(16.2)$ & $10(12.2)$ & $29(14.6)$ & \multirow{7}{*}{$0.321 *$} & $15(9.9)$ & $11(31.4)$ & $26(14.0)$ & \multirow{7}{*}{$0.014^{*}$} \\
\hline $10-19$ & $22(18.8)$ & $14(17.1)$ & $36(18.1)$ & & $22(14.6)$ & $8(22.9)$ & $30(16.1)$ & \\
\hline $20-29$ & $27(23.1)$ & $17(20.7)$ & $44(22.1)$ & & $37(24.5)$ & $7(20.0)$ & $44(23.7)$ & \\
\hline $30-39$ & $15(12.8)$ & $19(23.2)$ & $34(17.1)$ & & $26(17.2)$ & $6(17.1)$ & $32(17.2)$ & \\
\hline $40-49$ & $17(14.5)$ & $15(18.3)$ & $32(16.1)$ & & $30(19.9)$ & $2(5.7)$ & $32(17.2)$ & \\
\hline $50-59$ & $10(8.5)$ & $6(7.3)$ & $16(8.0)$ & & $15(9.9)$ & $1(2.9)$ & $16(8.6)$ & \\
\hline$\geq 60$ & $7(6.0)$ & $1(1.2)$ & $8(4.0)$ & & $6(4.0)$ & $0(.0)$ & $6(3.2)$ & \\
\hline \multicolumn{9}{|l|}{ Sex } \\
\hline Female & $42(35.9)$ & $22(26.8)$ & $64(32.2)$ & \multirow{2}{*}{$0.178 * *$} & $44(29.1)$ & $15(42.9)$ & $59(31.7)$ & \multirow{2}{*}{$0.116^{*}$} \\
\hline Male & $75(64.1)$ & $60(73.2)$ & $135(67.8)$ & & $107(70.9)$ & $20(57.1)$ & $127(68.3)$ & \\
\hline \multicolumn{9}{|l|}{ Occupation } \\
\hline Agriculture & $23(20.2)$ & $9(11.0)$ & $32(16.3)$ & \multirow{8}{*}{$0.000 *$} & $29(19.3)$ & $3(9.1)$ & $32(17.5)$ & \multirow{8}{*}{$0.002 *$} \\
\hline Business & $9(7.9)$ & $14(17.1)$ & $23(11.7)$ & & $21(14.0)$ & $1(3.0)$ & $22(12.0)$ & \\
\hline Service & $1(.9)$ & $12(14.6)$ & $13(6.6)$ & & $13(8.7)$ & $0(.0)$ & $13(7.1)$ & \\
\hline Student & $36(31.6)$ & $20(24.4)$ & $56(28.6)$ & & $31(20.7)$ & $17(51.5)$ & $48(26.2)$ & \\
\hline Labour & $24(21.1)$ & $11(13.4)$ & $35(17.9)$ & & $26(17.3)$ & $8(24.2)$ & $34(18.6)$ & \\
\hline House maker & $14(12.3)$ & $6(7.3)$ & $20(10.2)$ & & $17(11.3)$ & $1(3.0)$ & $18(9.8)$ & \\
\hline Unemployed & $2(1.8)$ & $2(2.4)$ & $4(2.0)$ & & $2(1.3)$ & $2(6.1)$ & $4(2.2)$ & \\
\hline None & $5(4.4)$ & $8(9.8)$ & $13(6.6)$ & & $11(7.3)$ & $1(3.0)$ & $12(6.6)$ & \\
\hline \multicolumn{9}{|l|}{ Education } \\
\hline Illiterate & $31(26.5)$ & $5(6.1)$ & $36(18.1)$ & \multirow{3}{*}{$0.000^{*}$} & $26(17.2)$ & $7(20.0)$ & $33(17.7)$ & \multirow{3}{*}{$0.708^{*}$} \\
\hline Literate & $81(69.2)$ & $69(84.1)$ & $150(75.4)$ & & $114(75.5)$ & $27(77.1)$ & $141(75.8)$ & \\
\hline None & $5(4.3)$ & $8(9.8)$ & $13(6.5)$ & & $11(7.3)$ & $1(2.9)$ & $12(6.5)$ & \\
\hline \multicolumn{9}{|l|}{ Districts } \\
\hline Jhapa & $63(53.8)$ & $49(59.8)$ & $112(56.3)$ & - & $85(56.3)$ & $22(62.9)$ & $107(57.5)$ & \multirow{2}{*}{ - } \\
\hline Morang & $54(46.2)$ & $33(40.2)$ & $87(43.7)$ & - & $66(43.7)$ & $13(37.1)$ & $79(42.5)$ & \\
\hline
\end{tabular}

Figures in parentheses indicate percentage with in mosquito transmit malaria

Discussion

During the study period July - August 2007, a total of 199 samples analysed, $112(56.3 \%)$ were from Jhapa and 87 (43.7\%) from Morang district. 16.1\% (32/112) cases were confirmed as malaria after microscopic investigation; Out of which $12.5 \%$ (25/199) were Plasmodium vivax, $3.1 \% \quad(6 / 199) \quad$ Plasmodium falciparum, and $0.5 \%(1 / 199)$.with mixed infection $(P$. vivax $+P$. falciparum). Slide Positivity Rate (SPR) in Jhapa and Morang was found 22.3\% (25/112) and 8.0\% (7/87) respectively. In the year 2004/2005, there were 967 positive cases of malaria in Jhapa, among which 344 cases were $P$. falciparum and $623 P$. vivax cases. Where as in the same year, there were 113 positive cases of malaria in Morang district among which 14 cases were $P$. falciparum and 99 were $P$. vivax ${ }^{6 .}$ In Nepal, malaria transmission occurs mainly in rainy season (highest between June and August) ${ }^{12}$. We collected samples during rainy season which represents almost same proportion of the cases for the whole year. Higher SPR in current study might be due to high mobility of the people in Jhapa with motorable (road) border points with India, low sample size, short period of study and inclusion of the patients having at least one symptom compatible to the malaria comparing to DoHS report 2004/2005.

Higher numbers of male were infected than females may be due to outdoor activities of male in the late 
evening, which is consistent with the similar other research findings ${ }^{13}$.

Peoples doing physical activities like labourers were among the most infected, which may be due to their nature of work which compels them to stay outside till late in the evening and even some of them sleep outside the home during summer thinking that if they stay out of the low height huts (Chhapro) they may get fresh air suitable for sleep. Overall, the low socio-economic status of the labourers may be the factor for acquiring the disease.

SPR was highest in patients of 20-29 years age group, which may be because the young adults work outside the home in the paddy fields, nurseries than the people of other age groups. Excessive outdoor activity in this age group may have attributed to the high infection rate. This finding is similar to the similar findings of Joshi, in 2004, who reported $P$. vivax infected patients were mostly $33.9 \%(69 / 203)$ in the age group of $16-30$ years ${ }^{14}$. In present study, we could not found any correlation of age group with parasitemia $(\mathrm{P}=0.748)$, which is similar as reported by Sherchand in $2002^{15}$.

In this study, 41.2\% (82/199) respondents have knowledge of malarial transmission, which is in disagreement with Chand's study report of $96 \%$ respondents had knowledge of malaria transmission by the bite of mosquito ${ }^{16}$ and Kaona et al. report from Zambia showed no association between educational level and knowledge of causes of malaria ${ }^{18}$. This difference may be due to lower no of samples and representation of only 2 districts as compared to countrywide participation in the other study. However, this result represents the ground reality.

In present study, knowledge on malaria transmission was found significantly associated with occupation and education $(\mathrm{P}<0.001)$, which is in agreement with Rasania et al. reported in Delhi as literacy status as a sole predictor of knowledge about malaria ${ }^{17}$ and also Sharma' finding of higher educational status more associated with correct knowledge about mosquito causing malaria ${ }^{2}$

In present study $69.7 \%(138 / 199)$ of respondents had knowledge of the symptoms. Fever was the commonest symptom mentioned by $68.3 \%(136 / 199)$ of the respondents and headache by $18.6 \%(37 / 199)$. As the malaria in this region is known as the 'Aaulo Jwaro', respondents may have mentioned the symptoms fever. Other symptoms noticed by them were fever with headache, fever with weakness, and fever with shivering and sweating; which is in agreement with Matta et al. who interviewed a total of 200 fever cases where majority of patients, $99(49.5 \%)$ enumerated two symptoms of malaria (fever/chills) followed by $61(30.5 \%)$ patients who could enumerate three symptoms ${ }^{19}$. Many other studies have shown that respondents have an idea about 2-3 symptoms of malaria ${ }^{17,20,21}$.

In this study, $35(17.6 \%)$ respondents did not know about whether malaria can be treated, this is little lower than similar other study ${ }^{16}$ with $98.60 \%$ had idea that it is treatable; in another study ${ }^{22} 51 \%$ respondents believed that malaria could be cured.

Present study findings shows that $33 \%$ volunteers were aware of the fact that malaria can be prevented by using bed nets were, while $26 \%$ believe it can be prevented with the improvement in sanitation and $6 \%$ believe in the use of smoke, $5.5 \%$ believe that it can be prevented with the use of prophylactic treatment and $3.5 \%$ believe in the use of repellent. This is in agreement with the similar other studies by Sherchand in 2002 and Das et al. in 2007 from Nepal ${ }^{15,22}$. Similar study by Chand reported bed-nets were used by $50.99 \%$ and smoking by $28.22 \%{ }^{15}$. Similarly in neighbouring country India, mosquito net was found to be a preferred method to avoid mosquito bite by Tyagi et al. ${ }^{23}$. Matta et al. reported $34 \%$ respondents mentioned mosquito net as a prime preventive measure against mosquito bite ${ }^{19,24}$.

\section{Conclusion}

Both the eastern terai districts are still endemic to malaria; Jhapa with higher SPR than Morang. Most of the infections have shown association with travel to other endemic areas in India and Nepal. Health education is a vital part lacking in improving the condition, justified with higher percentage of illiterate and labourers class people infected as compared to others. Education of the use of bed nets is insufficient and needs more aggressive health education to improve the condition in coming days.

\section{Acknowledgement}

The authors would like to acknowledge Central Department of Microbiology, Tribhuvan University, Epidemiology Disease Control Division, Kathmandu, and District Public Health Office, Jhapa and Morang for their cooperation during the study.

\section{References}

1. Gallup JL, Sachs JD. The economic burden of malaria. Am J Trop Med Hyg. 2001;64:85-96.

2. Sharma AK, Bhasin S, Chaturvedi S. Prediction of knowledge about malaria in India. J Vect Borne Dis. 2007;44:189-97.

3. WHO. World Malaria Report 2008. Geneva, Switzerland: WHO Media centre; 2008. 
4. WHO-SEARO. Malaria Disease Burden in SEA Region, WHO Regional Office for South-East Asia. New Delhi India: WHO Regional Office for South-East Asia; 2008.

5. Department of Health Services (DoHS). Annual report, Kathmandu, Nepal. Kathmandu: Department of Health Services, His Majesty's Government of Nepal; 2004/2005.

6. EDCD. Annual Report. Kathmandu, Nepal: Epidemiology and Disease Control Division, Department of Health Service, Ministry of Health (MoH), Nepal; 2005. p. 1-151.

7. Yadav SP, Tyagi BK, Ramanath T. Knowledge, attitude and practice towards malaria in rural communities of the epidemic prone Thar desert, northwestern India. J Com Dis. 1999;3:12736.

8. Collins KA, Samuel KD, Edwin AA, Kwadwo A, Korum, Francis KN. Malaria related beliefs and behavior in southern Ghana: implications for treatment, prevention and control. Trop Med Int'l Health. 1997;2:488-99.

9. Cheesbrough M. District Laboratory Practice in Tropical Countries, Part 1. UK: Cambridge University Press; 1999. p. 239-59.

10. Moody A. Rapid diagnostic tests for malaria parasites. Clin Microbiol Rev. 2002;15(1):6678.

11. Centres for disease control and prevention. Diagnostic procedure, Microscopic examination. [cited 2007 Oct 29]; [1 screen]. Available from URL:http://www.dpd.cdc.gov/ dpdx/HTML/Frames/DiagnosticProcedures/ body_dp_bloodexamin.htm

12. CIWEC Clinic. Malaria in Nepal: Advise for the short term traveler [homepage in the Internet]. [updated 2006 July 5; cited 2008 May 7];[1 screen]. Available from: URL:http://www. ciwec-clinic.com.

13. Wijeyaratne PM, Valecha N, Joshi AB, Singh D, Pandey S. Environmental Health Project. Activity report-130: An inventory on malaria Drug Resistance in Bangladesh, Bhutan, India and Nepal [Homepage in the Internet]. [updated June, 2004; cited 2007 Oct. 29] Available from: URL:http://www.ehproject.org/PDF/Activity_ Reports/AR-130\%20MDR\%20Inventory.pdf.

14. Joshi H. Report submitted on monoclonal Antibody based ELISA for detection of $P$. falciparum and $P$. vivax Antigens in malaria endemic populations in southern Nepal. J Nep Health Res Council. 2004; 2:43-6.

15. Sherchand JB. The value of malaria diagnosis: a preliminary study in the terai districts of Nepal. J Nep Health Res Council. 2002;1:21-4.

16. Chand KB, Mahat BB, Joshi YP, Joshi HR. Socio-Behavioral epidemiology and ecological determinants of malaria outbreak in Kanchanpur district - A report. Kathmandu: Nepal Health Research Council, Ministry of Health; 2003.

17. Rasania SK, Bhanot A, Sachdev TR. Awareness and practice regarding malaria of catchment population of a primary health centre in Delhi. J Com Dis. 2002;34:78-84.

18. KaonaF, SiajuanzaMT, Manyando C, Khondowe S, Ngoma GK. Utilisation of malarial drugs at a household level, results from a Knowledge Attitude and Practice study in Choma, southern province and Mporokoso, Northern Province of Zambia. Cent Afr J Med. 2000;46:268-70.

19. Matta S, Khokhar A and Sachdev TR. Assessment of knowledge about malaria among patients reported with fever: a hospital-based study J Vect Borne Dis. 2004;41:27-31.

20. Ongore D, Kamunvi F, Knight R, Minawa A. Study of knowledge, attitude and practice (KAP) of a rural community on malaria and the mosquito vector. East African Med J. 1989;66:79-89.

21. Singh TG, Singh RKN, Singh EY. A study of knowledge about malaria and treatment seeking behaviour in two tribal communities of Manipur. Indian J Pub Health. 2003;47:61-5.

22. Das NG, Talukdar PK, Kalita J, Baruah I, Sribastava RB. Malaria situation in forestfringed villages of Sanitpur district (Aasam), India bordering Arunchal Pradesh during an outbreak. J Vect Borne Dis. 2007;44:213-8.

23. Tyagi P, Roy A, Malhotra MS. Knowledge, awareness and practices towards malaria in communities of rural, semi-rural and bordering areas of east Delhi (India). J Vect Borne Dis. 2005;42:30-5.

24. Mac Cormack CP, Snow RW. Gambian cultural preferences in the use of insecticide-impregnated bed nets. J Trop Med Hyg. 1986;89:295-302. 